\title{
Revista Movimento: análise dos sentidos e da repercussão de um periódico que "se faz" no campo da Educação Física brasileira
}

\author{
Marco Paulo Stigger * \\ Maitê Vênuto de Freitas ** \\ Solange Rydz *** \\ Mauro Myskiw ****
}

\begin{abstract}
Resumo: Identificando a revista Movimento como uma instituição vinculada à história da Escola de Educação Física da Universidade Federal do Rio Grande do Sul, nesse artigo buscamos compreender como ocorreu o processo da sua produção/repercussão, a partir do momento em que se especializou como um periódico da educação física em interface com as ciências humanas e sociais (2003-2010). As respostas vinculadas a esse objetivo foram obtidas a partir de análises de entrevistas semi-estruturadas realizadas com editores e ex-editores do periódico, assim como com pessoas em destaque no contexto da acadêmico/científico da Educação Física Brasileira; também foram analisados documentos vinculados à produção periódica em geral e à revista Movimento em particular. Pode-se concluir que o processo de especialização da revista se vinculou à tensão existente no campo acadêmico/científico da Educação Física Brasileira. O sentido deste periódico não é redutível à socialização do conhecimento, mas engloba, também, um sentido de representatividade e de avaliação/classificação no campo, com profundos vínculos com a pós-graduação, com quem tem uma imbricação visceral. Isto fez parte de um processo que se impulsiona no momento de sua especialização e outros esforços vinculados às lógicas do campo científico. A revista Movimento é, assim, produto e resultado do seu desenvolvimento e do desenvolvimento da subárea das socioculturais, onde se consolida como um capital.
\end{abstract}

Palavras-chave: Publicações periódicas como assunto. História. Educação Física. Sociologia.

\footnotetext{
*Docente da Escola de Educação Física e do Programa de Pós-Graduação em Ciências do Movimento Humano da Universidade Federal do Rio Grande do Sul, Porto Alegre, RS, Brasil. Email: stigger@adufrgs.ufrgs.br

**Discente do Curso de Graduação em Educação Física da Universidade Federal do Rio Grande do Sul, Porto Alegre, RS, Brasil. E-mail: venutodefreitas@gmail.com

***Discente do Curso de Graduação em Educação Física da Universidade Federal do Rio Grande do Sul, Porto Alegre, RS, Brasil. E-mail: solesef@gmail.com

****Docente da Universidade Estadual do Oeste do Paraná, Marechal Cândido Rondon, PR; discente do Programa de Pós-Graduação em Ciências do Movimento Humano da Universidade Federal do Rio Grande do Sul, Porto Alegre, RS, Brasil. E-mail: mmyskiw@hotmail.com
} 


\section{INTRODUÇão}

No momento em que a Escola de Educação Física da Universidade Federal do Rio Grande do Sul (UFRGS) comemora os seus 70 anos de existência, há muitas razões para comemorar. Há, também, inúmeros motivos para tentarmos compreender - no contexto dessa história - o papel que essa instituição vem desempenhando no âmbito da Educação Física Brasileira, através das suas várias formas de participação.

Uma das suas intervenções nesse universo foi a criação da revista Movimento, que, de imediato, no seu primeiro número, em 1994, mostrou a sua intenção de induzir a comunidade da educação física a pensar sobre as suas especificidades. Este espírito já estaria ali presente na seção "temas polêmicos", por onde reconhecidos intelectuais da área foram provocados a responder a uma questão provocativa: "O que é Educação Física?" De imediato esse tema causou grande impacto, repercutindo réplicas e tréplicas não apenas no corpo da própria revista, mas também no seio da comunidade, em diferentes contextos e situações.

Tendo surgido como uma revista de caráter multidisciplinar, em 2003, quando concluía nove anos de existência, a Movimento passou por um processo de "especialização", e começou a publicar apenas artigos da área sociocultural e pedagógica. Isso aconteceu por duas razões. Primeiramente pelas novas exigências sobre avaliação de periódicos, pelas quais eram criticadas as revistas do tipo "guarda-chuvas" e valorizados os periódicos especializados. Em segundo lugar, pela resposta da própria comunidade, que a "elegeu" como um periódico das áreas sociais. Isso foi identificado num levantamento que mostrou que mais de $75 \%$ dos artigos nela publicados até então tinham origem na área sociocultural e pedagógica e que a maior parte da "massa crítica" que se propunha a publicar na Movimento (doutores e professores de cursos de pósgraduação) era de pesquisadores vinculados a este universo ${ }^{1}$.

\footnotetext{
${ }^{1}$ Mais detalhes sobre isso e outros aspectos da história do periódico podem ser encontrados no Editorial do volume 15, número 3 (EDITORIAL, 2009a).
} 
Com base nesses aspectos a revista se especializou e vem ocupando um lugar específico no campo acadêmico-científico da Educação Física Brasileira, ou seja, vem se constituindo um espaço onde os autores e leitores dessa área particular têm a possibilidade de publicar e ler artigos sobre temas afins.

Contudo, esse espaço não é apenas de difusão de conhecimentos específicos. Como seus editores consideraram no Editorial do seu volume 15, número 2 (EDITORIAL, 2009b, p. 8), "[...] as revistas científicas não são apenas veiculadoras de conhecimentos, mas também agentes que acabam por influenciar toda uma forma de pensar e de funcionar uma determinada área de conhecimento, com reflexos na intervenção relacionada a essa mesma área". É nesse sentido que a revista Movimento vem acolhendo pesquisadores da área sociocultural (com as suas produções), tendo influência, inclusive, nos rumos da pós-graduação em educação física, no Brasil, aspecto que será explorado no decorrer desse texto.

É em torno disso que esse artigo gravita. Nele buscamos compreender como ocorreu o processo da produção/repercussão da revista Movimento, a partir do momento em que se especializou como um periódico da educação física em interface com as ciências humanas e sociais (2003-2010). Isso foi desenvolvido a partir do olhar a sociologia da ciência, especialmente com base na noção de campo, na perspectiva de Pierre Bourdieu.

\section{UM OLHAR SOCIOLÓGICO SOBRE A CIÊNCIA E O LUGAR DOS PERIÓDICOS}

Em um artigo intitulado "O legado de Thomas Kuhn: o texto certo na hora certa", Clifford Geertz (2001) traz alguns comentários acerca da repercussão da obra "A Estrutura das Revoluções Científicas". Entre outros méritos por ele considerados, Geertz chama a atenção para o fato de que o trabalho de Kuhn foi capaz de aplicar o que ficou conhecido como a sociologia do conhecimento - um esforço para relacionar diferentes formas de construção do 
conhecimento ao contexto social, onde histórica e culturalmente são localizados e coletivamente produzidos - àquela que seria "[...] a mais prestigiosa, mais ameaçadora e [...] mais importante atividade intelectual de todas - as ciências naturais" (GEERTZ, 2001, p. 144). Segundo o autor, isso foi conseguido pelo afastamento de uma visão externalista da ciência - interessada nos seus efeitos e normas institucionais - para uma visão internalista, essa pautada pelas práticas científicas, com suas formas e interesses que se relacionam com uma determinada comunidade. Kuhn separaria, assim, a ciência vista como atividade intelectual (um modo de saber), da ciência como fenômeno social (um modo de agir) e, assim, teria desmistificado a autoridade científica e a incluído no tempo e na vida da sociedade.

Mesmo que tenha havido antecessores no que se refere a tentar compreender as relações sociais nas quais se insere a produção do conhecimento científico, não é difícil atribuir a Kuhn o reconhecimento de ter trazido à tona a idéia de que a ciência se constitui num processo social de convencimento e que o produto do trabalho científico se dá, menos na relação do pesquisador com a natureza e mais deste com uma comunidade da qual faz parte. Talvez mais do que pela difusão da noção de "paradigma", a importância desse trabalho se vincula à abertura de portas para uma perspectiva que leva a perguntar como funcionam as comunidades científicas, no que se refere às relações entre os indivíduos que constituem esses universos e como esses contextos se relacionam com outras dimensões da vida social, no que se refere à produção de conhecimento.

Esse ponto de vista se diferencia bastante da visão de que o conhecimento científico - e em especial sobre suas mudanças - se dá pautado por uma lógica sustentada exclusivamente na razão, como, por exemplo, quereria Popper (1975), a partir do "racionalismo crítico". Mesmo que essa perspectiva se aproxime à de Kuhn no sentido de que ambas concordem que o avanço na ciência não ocorre por um processo cumulativo, mas que os novos conhecimentos surgem pela derrubada dos anteriores, via debates, no contexto de uma comunidade, há entre elas uma diferença importante. Para Popper uma teoria seria considerada válida até que fosse falseada por 
argumentos contrários; para Kuhn um paradigma seria substituído por outro a partir do momento que uma comunidade considerasse que ele não estivesse dando mais respostas aos problemas que propusesse resolver. Se a primeira vista parece que há aí mais semelhanças do que diferenças entre eles, é crucial sublinhar que, para Popper, os processos racionais (lógicos) é que são determinantes para a legitimação ou para o falseamento de uma teoria, enquanto que, para Kuhn, são os processos (sociais) de convencimento acerca de um paradigma que levam ou não à sua derrocada.

Em que pese essa necessária ${ }^{2}$ simplificação acerca do pensamento desses autores, o que pretendemos destacar é que, sob o ponto de vista da Sociologia da Ciência, o foco é compreender como os processos sociais acontecem nesses universos e como interferem na aceitação (ou não) de determinadas verdades em diferentes áreas científicas.

É nessa direção que se desenvolvem as idéias de Pierre Bourdieu (1983a, 2004a, 2008a), o reconhecido sociólogo francês que, entre outros temas, estudou o universo social da ciência. Mesmo com diferenças e até críticas a Kuhn, Bourdieu (2008a) reconhece que este autor transformou profundamente o espaço dos teóricos da ciência da ciência, entre outros aspectos, por apontar que há uma distância entre pensar os métodos científicos pelas lógicas racionais e a partir de como acontecem na prática científica. A perspectiva de pensamento de Bourdieu se aproxima do ponto de vista de Kuhn, especialmente no que tange à idéia de comunidade científica e ao seu papel na legitimação (ou não) de determinadas formas de pensar cientificamente. Segundo Bourdieu (2008a), Kuhn teria introduzido a noção de autonomia do universo científico, mas não a teria elaborado enquanto tal. E é isso que ele tenta desenvolver a partir da "Teoria dos Campos" e da especificidade que denominou de "Campo Científico".

No sentido de Bourdieu ${ }^{3}$, as sociedades modernas são constituídas por relações de forças e por processos que as regulam,

\footnotetext{
${ }^{2}$ Impostos pelos limites de um artigo.

${ }^{3}$ Várias obras, entre elas Bourdieu (1983b, 1987, 1998 e 2008b).
} 
através do que se dão as mediações entre os agentes sociais e essa mesma sociedade. Na sua perspectiva isso pode ser analisado se considerarmos a idéia de "campos", identificados como espaços estruturados de posições estruturantes que têm determinadas características. Mesmo que um determinado campo tenha as suas especificidades - ou seja, se delimite pelos seus objetos de disputas e dos interesses específicos do próprio campo -, todos os campos possuem leis e propriedades que neles se expressam, estabelecendo as posições de cada indivíduo nestes espaços. Por essa razão, a compreensão de um campo (o campo da arte, por exemplo) oferece elementos úteis para a compreensão de outros.

Nesse contexto explicativo "o universo 'puro' da mais 'pura' ciência é um campo social como outro qualquer, com suas relações de força e monopólios, suas lutas e estratégias, seus interesses e lucros, mas onde todas essas invariantes revestem formas específicas" (BOURDIEU, 1983a, p. 122). Assim, a Sociologia da Ciência assenta-se na idéia de que o produto da verdade científica se relaciona com o produto das relações sociais da sua produção, ou seja, na estrutura e funcionamento do campo científico (BOURDIEU, 1983a).

Entendendo que "[...] a verdade [científica] é o conjunto das representações consideradas verdadeiras por serem produzidas segundo as regras que definem a produção da verdade [...]" (BOURDIEU, 2008a, p. 101), o autor se contrapõe a qualquer forma de compreensão do mundo da ciência que não leve em conta a noção de que é o campo científico que determina, a cada pesquisador, os seus problemas (políticos e científicos), com seus métodos e estratégias. Ele vai ainda mais adiante, afirmando que não há escolha científica (método, lugar de publicação, momento da publicação) que não seja uma estratégia política - um investimento - voltada para o lucro científico que, em última instância, é a obtenção do reconhecimento dos pares (BOURDIEU, 1983a).

Divergindo da idéia de comunidade científica num sentido homogêneo, pacífico, consensual, Bourdieu (1983a, p. 122-123) afirma que: 
[...] o campo científico, enquanto sistema de relações objetivas entre posições adquiridas (em lutas anteriores), é o lugar, o espaço de jogo de uma luta concorrencial. O que está em jogo especificamente nessa luta é o monopólio da autoridade científica definida, de maneira inseparável, como capacidade técnica e poder social; ou, se quisermos,o monopólio da competência científica, compreendida enquanto capacidade de falar e agir legitimamente (isto é, de maneira autorizada e com autoridade), que é socialmente outorgada a um agente determinado.

A situação abaixo, referida por Bourdieu a partir das idéias de Fred Reif, chama atenção para a dimensão concorrencial do campo científico:

Um cientista procura fazer as pesquisas que ele considera importantes. Mas a satisfação intrínseca e o interesse não são as suas únicas motivações. Isso transparece quando observamos o que acontece quando o pesquisador descobre uma publicação com os resultados a que ele estava quase chegando: fica transtornado, ainda que o interesse intrínseco de seu trabalho não tenha sido afetado. Isto porque o trabalho não deve ser interessante somente para ele, mas deve ser também importante para os outros (BOURDIEU, 1983a, p. 125).

Ao evidenciar o quanto é difícil separar as determinações propriamente científicas das que são propriamente sociais, esse excerto chama atenção para a relevância das publicações, vistas para além da sua função de comunicação e difusão do conhecimento - como formas de acumulação do capital científico, este só obtido pelo reconhecimento, não apenas das descobertas alcançadas, mas também dos seus autores. Apesar de existirem outros capitais acumuláveis $^{4}$ (como a sua instituição de origem, ter trabalhado com um pesquisador renomado, a sua capacidade de obter recursos, as recomendações que obtém de colegas e instituições, a sua visibilidade), entre os critérios que distinguem os pesquisadores está

\footnotetext{
4"Acumular capital é fazer um 'nome', um nome próprio, um nome conhecido e reconhecido" (BOURDIEU, 1983a, p. 132).
} 
a quantidade e qualidade dos trabalhos que ele venha a publicar. Não é por acaso que logo que um trabalho é concluído, o primeiro passo é torná-lo público através de um periódico reconhecido pela própria comunidade. Não é, também, por acaso a existência de inúmeras instituições voltadas para avaliação e classificação de periódicos, determinando a sua "qualidade" por análises de impacto e outras formas de categorização.

\section{Os Periódicos Científicos e o CAMPo da EduCAÇão FísicA, NO BRASIL}

No âmbito de qualquer comunidade científica é lugar comum que a comunicação entre pesquisadores e a divulgação dos resultados dos seus trabalhos ocorre, em grande parte, através de periódicos. Porém, a importância atribuída à produção em periódicos e a sua repercussão na avaliação dos pesquisadores que atuam na pósgraduação, tem causado bastante polêmica no caso brasileiro ${ }^{5}$. Seja pela sua lógica dita quantitativista (KUENZER; MORAES, 2005), seja pela pretensa desvalorização de outros atributos de um pesquisador (MOREIRA; HORTALE; HARTZ, 2004), seja pela concepção homogeneizada de ciência que a sustentaria (KERRPONTES et al., 2005), o fato é que muitas são as manifestações que criticam a centralidade que as publicações têm na avaliação de um pesquisador. Mas também é fato que há muitos argumentos que reforçam essa lógica e é essa perspectiva de avaliação de pesquisadores e cursos de pós-graduação que vem persistindo há algum tempo.

No contexto da Educação Física Brasileira esse assunto também é motivo de muitos debates. Não são poucos os trabalhos que refletindo sobre a influência dessa centralidade na avaliação da pósgraduação - põem em dúvida a sua eficácia. Um dos pontos dessa crítica se refere à caracterização acadêmica da educação física no

\footnotetext{
${ }^{5}$ Esse debate também ocorre em âmbito internacional. Aspectos disso podem ser observados em artigo recente (24/01/2011) do jornal Le Monde, cujo título é "Os pesquisadores são prisioneiros de uma corrida à publicação" (http://www.lemonde.fr/idees/article/2011/01/21/leschercheurs-sont-prisonniers-d-une-course-a-la-publication_1468155_3232.html)
} 
Brasil a partir da análise das subáreas que compõem os programas de pós-graduação nesse campo.

Edison Manoel e Yara Carvalho (2011) discutem esse tema, considerando que o termo genérico educação física é o preferido para denominar a maioria dos programas, mesmo que compartilhem diferentes subáreas: a biodinâmica e a sociocultural/pedagógica. Segundo eles, a biodinâmica destaca-se quando se considera o número de docentes por área e o número de linhas de pesquisa, o que se reflete como uma hegemonia que acaba por privilegiar a pesquisa orientada pelas ciências naturais em detrimento das humanas e sociais. Além dessa forma de construção da hegemonia, eles afirmam que a mudança no sistema nacional de avaliação da pós-graduação vem - desde 1998 - repercutindo nos rumos da pós-graduação brasileira em Educação Física. Eles acreditam que o sistema passou a supervalorizar a produção intelectual publicada em artigos de periódicos científicos, dando ênfase à indexação das revistas, tendo como referência a análise do impacto dos periódicos, obtida por metodologia advinda das ciências da informação, desenvolvida pelo Institute of Scientific Information (ISI). Como o número de periódicos indexados no ISI é muito maior nas áreas que conformam as denominadas ciências naturais, o impacto destes é bem maior do que os periódicos das ciências sociais e humanas. Assim, essa forma de avaliação viria a possibilitar maior espaço e melhores condições para a biodinâmica em detrimento das demais áreas, tendo em vista que sua produção é mais facilmente divulgada em periódicos da base ISI, devido à natureza das suas investigações. Como conseqüência, melhora-se a avaliação da biodinâmica e, paralelamente, com base numa concepção homogeneizada de ciência, as demais áreas são pressionadas para que acompanhem a lógica das ciências naturais.

Em artigo onde discute sobre uma política de publicação em Educação Física visando à qualidade dos periódicos, Go Tani (2007) também aponta para essas dimensões da tensão existente nesse campo e considera que um grande problema é a não definição da base epistemológica da educação física. Assim, o autor reconhece 
as dificuldades de quem publica nas áreas sociais e concorda que o quadro seja mais animador na área biológica. Mesmo propondo a reflexão sobre a viabilidade da utilização de indexadores internacionais para a avaliação dos programas de pós-graduação brasileiros, acaba por vê-los de uma forma positiva e por expressar que essas discussões devem continuar a compor a agenda sobre qualidade das publicações. Porém, ressalta: "[...] há que se tomar cuidado para que elas não sejam confundidas com a 'flexibilização' de critérios que, invariavelmente, resulta em 'nivelamento por baixo'" (TANI, 2007, p. 14).

Esse debate não se esgota no que foi referido acima, e não são poucos os autores que, nos últimos anos, vêm tratando dele, a partir de diferentes vieses ${ }^{6}$. Mas, na maior parte das vezes, essas discussões gravitam no entorno da tensão existente no campo, essa que é pautada pelas diferenças entre a educação física vista pelas ciências naturais e aquela analisada a partir das ciências sociais. Da nossa parte, interessa destacar que a revista Movimento - objeto da nossa análise - se constitui na relação com as tensões que ocorrem no campo da pós-graduação em educação física, no Brasil, com os conflitos acerca de diferentes concepções de ciência que existem nesse universo, e com as repercussões disso nos debates sobre a qualidade dos periódicos e dos pesquisadores.

É nesse contexto que se insere esse trabalho. Nele, cabe reforçar, procuramos compreender como ocorreu o processo da produção e repercussão da revista Movimento, a partir do momento em que ela se especializou. Considerando que esta decisão colocou esse periódico na contra-mão de uma hegemonia que parece existir na Educação Física Brasileira, procura-se entender como isso vem repercutindo nesse universo específico.

Com base em dados obtidos em entrevistas semi-estruturadas realizadas com editores e ex-editores do periódico ${ }^{7}$, assim como com pessoas em destaque (e influência) no contexto acadêmico/científico

\footnotetext{
${ }^{6}$ Entre outros, sugerimos a leitura de Kokobun (2003), Daolio (2007) e Lovisolo (2007).

${ }^{7}$ Foram entrevistados Vicente Molina Neto (ex-editor), Silvana Goellner (ex-editora e atual membro da Comissão de Avaliação da Área 21 da CAPES), Alex Branco Fraga (editor), Ivone Job (editora). Vale destacar que os três primeiros são docentes do Programa de Pós-Graduação em Ciências do Movimento Humano da UFRGS e que a última é discente deste programa.
} 
da Educação Física Brasileira ${ }^{8}$ e também a partir de documentos vinculados ao periódico, procuramos responder às perguntas: quais os sentidos dos periódicos científicos (em especial da revista Movimento) na relação com o campo acadêmico/científico da educação física e com os seus programas de pós-graduação? Como a revista Movimento "se faz" no campo acadêmico/científico da educação física?

\section{Sentidos dos Periódicos - Sentidos da ReVista Movimento}

Nesse tópico, vamos refletir sobre os sentidos dos periódicos para a educação física e seus programas de pós-graduação. Esses sentidos serão interpretados a partir da noção de interesse ou illusio ${ }^{9}$, isto é, a pronta adesão às necessidades do campo acadêmicocientífico derivada da correspondência entre a estrutura objetivada no campo considerado e a incorporada pelos agentes. A noção de Illusio é tratada no sentido de "estar preso ao jogo, preso pelo jogo, acreditar que o jogo vale a pena ou, para dizê-lo de maneira mais simples, que vale a pena jogar." (BOURDIEU, 2004, p. 139). Procuramos, especificamente, tratar dos interesses pelos periódicos, primeiro, em relação à área de conhecimento e, depois, em relação aos programas de pós-graduação.

\subsection{EM RELAÇÃO À ÁREA DE CONHECIMENTO: SOCIALIZAÇÃO, AVALIAÇÃO E REPRESENTAÇÃO}

Pouco se pode questionar que os periódicos científicos, sejam eles impressos ou on-line, encontram sentido na sua expectativa de

\footnotetext{
${ }^{8}$ Não tivemos oportunidade de entrevistar outras pessoas que poderiam ter ampliado as reflexões aqui propostas. Portanto, aproveitando a presença, na nossa instituição, de pesquisadores que se destacam por atuações em instâncias decisórias da pós-graduação brasileira, entrevistamos: Go Tani (docente do Programa de Pós-Graduação em Educação Física da USP, foi representante de área na CAPES e no CNPq); Juarez Vieira do Nascimento (docente do Programa de Pós-Graduação em Educação Física da UFSC, atual Coordenador Adjunto da Área 21 da CAPES); Valter Bracht (docente do Programa de Pós-Graduação em Educação Física da UFES, foi representante da área na CAPES).

${ }^{9}$ Sobre essa noção ver Bourdieu (2004b, p. 139-140; 2008b, p. 97-106; 2009, p. 108-109).
} 
divulgação, disseminação ou "socialização"10 do conhecimento produzido por uma determinada área de conhecimento. É nesse sentido que as seguintes afirmações de Go Tani e Juarez Vieira do Nascimento, a respeito do papel dos periódicos, correspondem à estrutura de relações objetivas do campo acadêmico:

Quem produz conhecimento quer disseminar esse conhecimento e precisa fazê-lo. Existem vários instrumentos de disseminação e um dos mais clássicos, e provavelmente o principal, continua sendo a revista. Então a revista é um instrumento essencial para a divulgação do que se faz em termos de ciência, de pesquisa, e claro que a Educação Física, por ser uma área de conhecimento devidamente inserida no contexto da Universidade, ela tem que ter mecanismos de disseminação que não seja simplesmente pelo curso de graduação e formação profissional ou pelo curso de extensão. Então, obviamente que a revista é fundamental e vai continuar sendo (TANI, 2010).

Você tem acesso aos artigos em algum portal, mas vejo a edição impressa com importância fundamental à intervenção do profissional, principalmente para subsidiar a nossa intervenção assim como também a melhoria da qualidade da formação inicial (NASCIMENTO, 2010).

O sentido relacionado à difusão do conhecimento que têm os periódicos é tão recorrente e naturalizado que, no decorrer das entrevistas, não mereceu muitas demandas na busca de aprofundamentos. Mas, na medida em que os questionamentos a respeito das revistas passaram a englobar a sua relação com a Coordenação de Aperfeiçoamento de Pessoal de Nível Superior (CAPES), com especificidades da área de educação física e com os programas de pós-graduação, outros sentidos atribuídos aos

\footnotetext{
${ }^{10} E s s a$ expressão é aqui utilizada no sentido "nativo" de disseminação, como muitas vezes ele é tratado no campo. Outros termos nativos foram e serão destacados entre aspas, por serem muitas vezes repetidas pelos agentes do campo, não apenas os que foram por nós entrevistados.
} 
periódicos foram emergindo, como: o seu lugar na avaliação e a classificação da pujança das áreas e subáreas de conhecimento; a sua caracterização como espaços representativos de subáreas, instituições, grupos e/ou de pessoas.

Segundo a posição dos nossos interlocutores, o conhecimento produzido nas diversas áreas de conhecimento e difundido através dos periódicos científicos, além de estar implicado na formação acadêmica e/ou na intervenção pedagógica/profissional, funciona como um "[...] importante instrumento de avaliação institucional, avaliação da área de conhecimento, avaliação do departamento, avaliação da Universidade, avaliação da atuação docente" (TANI, 2010). A partir dessa consideração percebe-se que não foi sem motivos que a área (acadêmica) de educação física comemorou ${ }^{11}$, nos últimos dois anos, a indexação ${ }^{12}$ internacional de seus periódicos no ISI Web of Knowledge $e^{13}$ (Movimento; Motriz da UNESP) e na SciELO Brasil ${ }^{14}$ (Motriz; Revista Brasileira de Ciências do Esporte; Revista Brasileira de Educação Física e Esportes).

Para além desse crescimento do número de revistas indexadas no cenário internacional, também o aumento de publicações em revistas internacionais é facilmente tomado como avanço/ desenvolvimento da área de Educação Física, isto é, uma "melhor" classificação da área, representando o progresso da pujança de sua produção acadêmica. A respeito disso, vale trazer um trecho da entrevista com Juarez Nascimento, na qual ele enfatiza este crescimento e o relaciona com o desenvolvimento da área:

\footnotetext{
${ }^{11}$ Não foram poucas as mensagens que circularam na WEB quando essas indexações aconteceram.

${ }^{12} \mathrm{Os}$ indexadores são entendidos neste trabalho como instituições/empresas de base de dados que ofertam serviços de [1] indexação e divulgação da produção científica (potencializando aspectos como visibilidade, acesso, citações) e de [2] mensuração ou avaliação das publicações (constituindo estratificações e hierarquizações através de sistemas de informação que formulam/ calculam índices ou fatores de impacto). Para figurar nos indexadores e continuar fazendo parte destes, os periódicos necessitam cumprir algumas regras, como regularidade, periodicidade, avaliação por pares, número de artigos originais, formação e representatividade dos editores, entre outras.

${ }^{13} \mathrm{O}$ ISI Web of Knowledge é uma plataforma eletrônica e compreende um importante indexador no cenário da catalogação, divulgação, acesso e avaliação da produção científica internacional (THOMSON REUTERS, 2010).

${ }^{14} \mathrm{~A}$ SciELO (Scientific Eletronic Library Online) Brasil é "[...] uma biblioteca eletrônica que abrange uma coleção selecionada de periódicos científicos brasileiros" (SCIELO, 2010).
} 
Em termos de índices de impacto da nossa produção em bases de referência internacional, nós aumentamos 300\% em termos de periódicos de alto impacto. Se nós fôssemos comparar com o desempenho observado no triênio passado, o índice de impacto dos nossos periódicos aumentou consideravelmente. Isto quer dizer que a área também tem buscado os periódicos de impacto, ou seja, nas principais bases indexadoras, o que não era uma característica da nossa área nos triênios anteriores [...]. Então isso contribuiu muito para o desenvolvimento da nossa área.

Já que a produção em periódicos é uma importante forma de avaliar a produção de conhecimento e os periódicos internacionais são os que mais têm peso na relação com os locais/nacionais, criase o interesse pelas revistas indexadas internacionalmente, sobretudo as que têm índice $\mathrm{H}$ ou fator de impacto ${ }^{15}$. Às revistas nacionais que quiserem "melhorar", "progredir", cabe a indexação nas bases internacionais visando colocar-se no "mesmo nível de avaliação e padronização". Este tipo de "conquista", por sua vez, na lógica de funcionamento do campo acadêmico, indica o progresso da área de conhecimento. Nessa lógica de progresso, afirma Go Tani (2010), não são todos os pesquisadores que buscam os periódicos internacionais e também não temos que pensar que os nacionais irão morrer, porque

[...] vai haver uma distribuição normal também em termos de produção científica: numa extremidade os periódicos locais, de um laboratório, de um grupo de estudo, etc., na outra extremidade um periódico de alto impacto com forte inserção internacional e a produção de cada um de nós vai estar dentro disso, não tem como, é assim (TANI, 2011).

\footnotetext{
${ }^{15}$ Duas avaliações dos periódicos consideradas importantes (utilizadas como referência pelo QUALIS-CAPES) são o Fator "j" do Journal Citation Reports - ISI Web of Knowledge (parâmetro para indicar a relevância das produções/periódicos no cenário científico, baseado no índice de citações dos artigos) e o Índice "h" da SCOPUS (parâmetro para indicar a produtividade dos pesquisadores - individuais ou em grupo -, oferecendo funcionalidades como identificação autores e filiações, análise de citações, análise de publicações) (PERIÓDICOS CAPES, 2010).
} 
Esta representação do progresso da área, relacionada com os espaços de publicações e suas indexações, implica na existência de um espaço acadêmico-científico socialmente estruturado - um campo científico - no qual os pesquisadores, os periódicos e as áreas de conhecimento disputam posições. Este campo considerado tem propriedades atuantes, regras imanentes que funcionam como forças objetivas (avaliadoras e classificadoras) inscritas nas ações cotidianas, nas rotinas dos agentes, instituições e áreas de conhecimento envolvidas. Estando todos estes enredados, acreditase que vale a pena jogar este jogo: tem-se a crença de que devemos publicar em revistas indexadas, de impacto, de que os periódicos devem estar indexados, bem classificados no Qualis-Periódicos ${ }^{16}$ da CAPES.

Se Go Tani advoga essa posição, Valter Bracht assume uma postura crítica em relação a esta situação. Quando questionado sobre a busca dos periódicos pelas indexações e melhores classificações, este pesquisador manifesta-se da seguinte forma:

Eu acho que a gente (o campo) deveria poder operar com maior autonomia em relação à CAPES e em relação a esses institutos indexadores, por exemplo, um pouco como a área da Educação faz. Eu ouvi falar que um dos candidatos da área da Educação Física a representante na CAPES tem a idéia de perguntar à comunidade, "quais são os nossos melhores periódicos de nossa área?" "São esses". "Muito bem, estão ranqueados para cima". Se são ISI, X ou Y, nesse momento, vamos dizer assim, é secundário; pode até almejar isso, mas o que é importante é elevar a qualificação dos periódicos que a comunidade considera importantes. O sujeito, que por razões outras consegue colocar o periódico numa posição boa no Qualis, acaba sendo supervalorizado em detrimento de um que tem uma

\footnotetext{
${ }^{16}$ O Qualis-Periódicos da CAPES compreende a estratificação (A1, A2, B1, B2, B3, B4, B5 e C) das revistas, por áreas, com a finalidade de avaliar os Programas de Pós-Graduação, pois cada estrato corresponde a uma pontuação. Esta estratificação está baseada, fortemente, nas indexações e nos fatores de impacto dos periódicos nos quais orientadores e estudantes dos programas publicam (ver CAPES, 2010a).
} 
repercussão da área muito maior. Assim, eu vejo com um certo ceticismo esse processo. Gostaria que a área pudesse ter mais autonomia, tanto frente à CAPES, quanto em relação a esses indexadores (BRACHT, 2010).

É aqui que parece fazer sentido a legitimação do Qualis-Livro ${ }^{17}$, identificado como um aspecto que se relaciona com o sentido avaliador e classificador das publicações periódicas no campo da educação física. Ele é resultado de uma disputa interna do campo acadêmico para validar outro tipo de capital e equilibrar as configurações (posições relativas) que, também no caso da educação física, envolve disputas entre pesquisadores, grupos, programas, instituições, etc.

Go Tani, Juarez Nascimento e Silvana Goellner, ao comentarem sobre este assunto, afirmam que a avaliação dos livros encontra sentido na educação física e sua legitimação institucional é importante:

[...] essa valorização da publicação em forma de livros, capítulos de livros, foi exatamente para contemplar aquilo que nos é inerente em termos de características acadêmicas e científicas, e também para amortecer algumas disputas que eu não vejo muito sentido. Essa disputa se a Educação Física é biológica ou é sociocultural, a Educação Física, goste ou não goste, é tudo isso [...]. (TANI, 2010).

Outro aspecto que é importante destacar em relação aos periódicos científicos é que não é somente a produção intelectual de periódicos que é importante para a área, mas também a produção científica veiculada nos livros e capítulos de livros (NASCIMENTO, 2010).

[...] a Movimento impactou na produção assim como capítulo de livro também impactou, que foi outra briga política dentro da área para que houvesse o reconhecimento de livros e capítulos de livros (GOELLNER, 2010).

\footnotetext{
${ }^{17}$ O Qualis-Livro da CAPES também é uma forma de avaliação dos Programas de PósGraduação, considerando a produção dos docentes e discentes, operacionalizada pela estratificação das suas obras publicadas no formato livro (ver CAPES, 2010b).
} 
Não queremos, aqui, discutir a divisão ou fragmentação da área da educação física, tão pouco colocar os periódicos e os livros como as únicas formas de posicionamento no campo acadêmico. Mas tendo claro que "publicar ou perecer"18 é uma regra nesse universo, o objetivo de trazer essa discussão sobre a validação dos livros e capítulos de livros em relação a validação dos artigos em periódicos, foi de colocar elementos para engrossar nosso argumento de que os periódicos ocupam lugar hegemônico nas avaliações e classificações que se estabelecem na área, no que se refere às disputas entre seus diversos grupos.

Nessa mesma direção, chamou nossa atenção para um outro sentido dos periódicos científicos, o da representatividade. Ao mesmo tempo em que as revistas são espaços de "socialização" do conhecimento produzido e entram nos cálculos da avaliação e classificação de seus produtores, elas também podem funcionar como espaços de representação de grupos ou subáreas que, de maneira mais ou menos deliberada, tratam de criar e reforçar os seus espaços qualificados de produção, no que se refere à legitimidade do campo acadêmico. Um dos exemplos desse sentido atribuído aos periódicos é a revista Movimento - citada por Valter Bracht - que, após sua especialização, tem se constituído num espaço importante de publicação (portanto, avaliação e classificação) de um grupo de pesquisadores da área (ou sub-área) denominada de sociocultural em relação aos pesquisadores da biodinâmica:

[...] a Educação Física como área acadêmica, é uma área cindida, uma área dividida. Há uma forte tendência, no meu entendimento, de crescimento daquilo que se convencionou chamar de área biodinâmica - é na verdade a produção do conhecimento orientada mais nas ciências naturais - em detrimento da área que se convencionou chamar de sociocultural. Isso, em função das regras que estão colocadas, das regras que são claramente

\footnotetext{
${ }^{18}$ Esse é um axioma sistematicamente referido nos corredores da pós-graduação brasileira em geral e na Educação Física em particular. Sobre suas repercussões, ver Lovisolo (2007)
} 
favoráveis a uma determinada perspectiva de se fazer ciência, que desfavorece um grande grupo da Educação Física. Então, algumas revistas, particularmente algumas revistas brasileiras, tentam se qualificar, no caso mesmo da revista Movimento, e privilegiar a produção do conhecimento dentro da área que vamos chamar de sociocultural (BRACHT, 2010).

As palavras de Bracht estão de acordo com o que refere Go Tani, destacado em excerto anterior, no que diz respeito à identificação de uma disputa entre as áreas no contexto interno da educação física. Porém, é também possível perceber que não há um mesmo entendimento num outro aspecto: enquanto Go Tani acredita que não há sentido em algumas disputas, "[...] a Educação Física, goste ou não goste, é tudo isso [...]" (TANI, 2010), Bracht considera que algumas "[...] regras que são claramente favoráveis a uma determinada perspectiva de se fazer ciência, que desfavorece um grande grupo da Educação Física" (BRACHT, 2010). Na perspectiva de Bracht, o que parece estar em jogo, não é meramente o fato de existirem diferentes áreas no campo e todas comporem a educação física. O que ele aponta é o fato de haver uma hegemonia de uma delas, essa atravessada por concepções distintas e distintivas de ciência e de educação física. E é isso que acaba por determinar o que, nesse universo, é a boa ciência e o que é a boa educação física.

Podemos dizer, então, que as disputas internas da área de educação física passaram/passam pelas revistas, foram/são mediadas/atualizadas por elas e, de certa forma, as constituem. Não é de se estranhar que na sua entrevista Go Tani (2010), dando grande importância à lógica de funcionamento do campo acadêmicocientífico, assevere, em tom negativo, que a revista do Colégio Brasileiro de Ciências do Esporte (RBCE) "[...] foi utilizada como instrumento de disputas ideológicas, político, sociopolítico, e assim por diante" e que, sobre o mesmo periódico, Valter Bracht (2010), dando importância a noção de intervenção pedagógica, afirme que, 
em tom positivo, que a revista teve "[...] uma importância política enorme e foi um pólo de resistência a uma determinada visão de ciência que tinha se instalado no campo".

Isso nos leva a pensar sobre o surgimento e investimento institucional (representativo) de vários periódicos generalistas (Revista Brasileira de Ciências do Esporte; Revista Paulista de Educação Física, atualmente Revista Brasileira de Educação Física e Esporte; revista Motriz; Revista da Educação Física da UEM, entre outras), mas também de periódicos especializados (Movimento; Revista de Brasileira de Cineantropometria \& Desempenho Humano; Revista Brasileira de Medicina do Esporte; Licere; Pensar a Prática; Motrivivência; entre outras). Estas informações colaboram com o nosso raciocínio de que - para além da difusão do conhecimento - as revistas científicas compreendem uma importante forma de representação da área de educação física, de subáreas, de universidades, de programas de pós-graduação, de associações científicas, etc.

O fato dos periódicos assumirem esse sentido de representatividade simultaneamente ao de avaliação/classificação e de socialização do conhecimento/produção - que são transpassados pelas disputas do campo da educação física - nos coloca a dimensão do poder dos periódicos, especificamente, dos editores, suas comissões e conselhos editoriais, na mediação que fazem em vista do desenvolvimento da área e/ou da própria revista.

\subsection{Em Relação aos programas de Pós-Graduação: uma IMBRICAÇÃO VISCERAL}

$\mathrm{Na}$ área da educação física (e em outras, certamente) os periódicos e os programas de pós-graduação stricto sensu (mestrado e doutorado) estabelecem uma relação muito próxima. A pós- 
graduação como "importante" espaço de produção de conhecimento científico e os periódicos como "importante" espaço de divulgação, "socialização" dos conhecimentos, como também de avaliação, classificação e de representação dos agentes e seus programas. Nesse cenário, vale lembrar, ainda, da $\operatorname{Capes}^{19}$ e do $\mathrm{CNPq}^{20}$, "importantes" órgãos governamentais de fomento à pesquisa e à formação, bem como de avaliação (controle, regulação) dos agentes e programas.

Como vimos, o interesse pela publicação em periódico é uma maneira de socializar, ser avaliado, ser classificado e ser reconhecido no campo. Ele refere-se a uma forma de estar no campo acadêmico da educação física, de "[...] participar, admitir, portanto, que o jogo merece ser jogado e que os alvos engendrados no e pelo fato de jogar merecem ser perseguidos; é reconhecer o jogo e reconhecer os alvos" (BOURDIEU, 2004b, p. 139). É isso que faz com que os coordenadores, docentes e discentes dos programas de pósgraduação vejam nas revistas uma oportunidade para o "desenvolvimento" da área, do programa e do currículo. De outro lado, as revistas, com seus interesses, contam com a submissão dos trabalhos produzidos no âmbito dos programas de pós-graduação, para "fechar" seus fascículos com "qualidade", daí a necessidade de esforços para estar "bem avaliada", pois os que têm interesse em publicar também olham para a classificação da revista, já que, estando ela classificada, além de disseminar a informação, classifica autor, seu programa, sua instituição, sua área.

Não é despropositada essa nossa ênfase neste sentido classificatório dos periódicos na relação com a pós-graduação. Ela assume tamanha proporção que o uso de expressões como "lógica produtivista", "geração Lattes" são frequentemente utilizadas para se referir ao fato de que a "utilidade" do conhecimento produzido e

\footnotetext{
${ }^{19} \mathrm{~A}$ CAPES, na sua apresentação institucional aponta como seu propósito o "[...] papel fundamental na expansão e consolidação da pós-graduação stricto sensu (mestrado e doutorado) em todos os estados da Federação" (CAPES, 2010c).

${ }^{20} \mathrm{O}$ Conselho Nacional de Desenvolvimento Científico e Tecnológico (CNPq) é uma agência do Ministério da Ciência e Tecnologia (MCT) "[...] destinada ao fomento da pesquisa científica e tecnológica e à formação de recursos humanos para a pesquisa no país" (CNPq, 2011).
} 
publicado pode não figurar como primeiro critério de escolha de uma revista. Valter Bracht e Go Tani se referem a esse aspecto com tom de preocupação para a área:

[...] isso é um pouco da lógica produtivista que a pós-graduação vem adotando, que se transmite para os concursos, etc., que faz com que o sujeito antes de publicar, não pergunte quem vai ler e que impacto vai ter isso; impacto aqui, no sentido da intervenção, do uso, vamos dizer assim, desse conhecimento, a utilidade que esse conhecimento pode ter e, sim, se pergunte qual é a posição do periódico no Qualis (BRACHT, 2010).

Outro sinal amarelo que eu vejo, que está diretamente vinculado com esta questão de periódicos nacionais e internacionais, é o que eu tenho chamado de "geração Lattes". Esse pessoal - geração Lattes - não está nem aí com a especificidade da área do conhecimento, não está nem aí com nada, está simplesmente buscando o que? Status acadêmicos individuais (TANI, 2010).

Nos bastidores da revista Movimento este efeito pode ser notado quando se observa, que nos últimos dois anos - especialmente após sua indexação no ISI Web of Knowledge e a estratificação como B1 no Qualis-Periódicos da área -, houve um aumento do número de submissões fora do seu escopo ${ }^{21}$. Em 2010, estas submissões somam 22\%; isto é, 52 artigos de um total de 236 submissões foram enviados sem a devida adequação. Tal número pode indicar que, em vários casos, não é o escopo da revista a informação mais relevante para a tomada de decisão de submissão, mas sim a sua classificação e indexação. Silvana Goellner, num tom de crítica, reforça que essa lógica existe:

\footnotetext{
${ }^{21} \mathrm{Na}$ página de entrada da Plataforma Eletrônica da Revista Movimento é informado que ela "tem por objetivo publicar pesquisas científicas sobre temas relacionados à Educação Física em interface com as Ciências Humanas e Sociais, em seus aspectos pedagógicos, históricos, políticos e culturais".
} 
Hoje, eu tenho que atingir trezentos pontos com algumas travas, mas eu posso fazer isso pulverizando a minha publicação para vários estratos: desde o B4, B5 até o A1 [...]. Bom, eu sei que tem uma revista que vale cinco pontos, mas eu posso ter três [revistas]. Eu já vou ter quinze [pontos]. Isso porque têm as travas, B1 a B5, eu posso ter três. Então quinze pontos já ajudam. Jogo mais tantos pontos aqui, então é um cálculo matemático e as revistas, o quanto elas valem, o quanto elas estão pesando aí. Eu vejo um movimento que talvez esteja acontecendo: primeiro eu mando para uma revista mais pesada [...]; se não passar lá eu mando para uma B2. E, se não passar eu vou diminuindo, mas eu tento publicar esse texto - eu não - mas as pessoas estão tentando fazer esse movimento (GOELLNER, 2010).

Nesta configuração de "estratos", "pontuação" e de "cálculos" no qual os periódicos estão posicionados, não é de se surpreender que tenhamos recebido uma solicitação feita por um autor que teve seu trabalho aprovado na revista Movimento, mas precisava saber quando seria publicado, tendo em vista que dependia dos "pontos" relativos àquela publicação para ser credenciado no programa de pós-graduação pretendido.

Nessa perspectiva da pontuação dos docentes para atender aos critérios de entrada e permanência nos programas de pósgraduação ${ }^{22}$, Silvana Goellner se refere ao "peso" da revista Movimento nas avaliações, quando esta atingiu o estrato B1, onde um artigo passa a contabilizar 60 pontos. Para esta pesquisadoradocente, este periódico, "valendo esta pontuação", ocupou lugar central na avaliação dos docentes vinculados às pesquisas socioculturais, que têm modos de produção específicos, diferentes das ciências biomédicas. Segundo ela, não raro, os pesquisadores-docentes das áreas socioculturais eram/são considerados improdutivos, "puxando o programa para baixo" no conceito da CAPES. Nesse sentido, o reconhecimento da revista Movimento estaria relacionado ao

\footnotetext{
${ }^{22}$ São critérios conhecidos e reconhecidos no campo sobre os quais não vale discorrer.
} 
reconhecimento das pesquisas em interface com as ciências humanas e sociais no âmbito da pós-graduação. Tal dimensão compõe o discurso de Silvana Goellner e Vicente Molina Neto, quando afirmam que:

[...] eu claramente percebi que nessa última avaliação [...] como a Movimento contribuiu, impulsionou os vários programas de pós-graduação e, mais do que isso, ela cortou a possibilidade de que alguns professores e de que algumas linhas de pesquisa fossem extintas, fundamentalmente aquelas vinculadas às áreas das humanas que é a grande disputa que ainda está colocada; mais amena, mas que ainda está colocada (GOELLNER, 2010).

[...] na minha opinião a revista Movimento foi uma das $[\ldots]$ que contribuiu significativamente para solidificar essa área das humanas e sociais na Educação Física Brasileira [...]. O que acontece: toda a nossa produção nós começamos a escoar para duas revistas no Brasil, já que a gente não conseguia publicar fora do país, por uma série de preconceitos, de desentendimentos e de outras coisas. Nós tínhamos duas possibilidades de publicação no Brasil: a RBCE e a Movimento. Então ela ajudou a nos solidificar, às linhas de pesquisa vinculadas à educação física escolar, representações sociais do movimento humano (MOLINA NETO, 2010).

Esta condição da revista Movimento nos colocou a analisar, ainda que rapidamente, o que chamamos de uma imbricação visceral entre os periódicos e os programas de pós-graduação, na qual, o "desenvolvimento" da revista reflete simultaneamente o "desenvolvimento" da área e vice-versa.

Um primeiro aspecto dessa condição envolve o pesquisadorparecerista. Se os pesquisadores das áreas socioculturais são acolhidos por revistas com esse escopo, estes não somente colaboraram "socializando" seus trabalhos nos periódicos, mas também são convidados a participarem como pareceristas dos periódicos, a envolverem-se na avaliação por pares dos trabalhos submetidos, qualificando o periódico também nesse sentido. Segundo 
Juarez Vieira do Nascimento, esta qualificação também ocorreu por uma demanda dos indexadores, pois

[...] os periódicos necessitam melhorar a sua qualidade a fim de buscar indexação nas principais bases de referência internacional. Assim, para atender esses requisitos de indexação, eles tiveram que buscar apoio dos docentes da pós-graduação, principalmente na emissão de pareceres. [...] a participação dos docentes assegurou um determinado nível de qualidade na análise dos artigos, resultando em maior rigor em termos das publicações (NASCIMENTO, 2010).

O resultado é que, pelo menos no caso da revista Movimento, grande parte dos avaliadores está ou esteve vinculada a programas de pós-graduação como docentes-pesquisadores ou discentespesquisadores $^{23}$; isto é, os trabalhos são avaliados pelos pares da área e dos programas. Com o "desenvolvimento" dos pesquisadores que são também os avaliadores especializados, ocorreu a qualificação do crivo dos trabalhos a serem publicados nos periódicos, conforme nos explicou Vicente Molina Neto, referindo-se à revista Movimento:

[...] de repente, como ela [a revista Movimento] foi se especializando, os artigos começaram a ser rejeitados. A história da pós-graduação da educação física ou na história da educação física, ela conseguiu - eu vou usar uma expressão que eu acho bem interessante, que define bem -, ela construiu uns seres mimados e mimosos [...]. Então, como a revista vai se qualificando, esses seres mimados e mimosos, eles começam a ter artigos rejeitados e aí há todo um processo de pressão: "Não, olha... mas como o meu artigo foi rejeitado? Quem é esse avaliador que?" (MOLINA NETO, 2010).

Outro aspecto do "desenvolvimento" dos programas de pósgraduação que podemos relacionar com a qualificação dos periódicos, este quantitativo, é o aumento da produção de artigos. Boa parte

\footnotetext{
${ }^{23} \mathrm{Os}$ ex-discentes têm sua formação no âmbito dos programas de pós-graduação e, dessa forma, estão inseridos no campo científico.
} 
das submissões dos trabalhos advém dos programas de pós-graduação, onde docentes e discentes são induzidos a publicar ${ }^{24}$. Mas, mais que isso, eles são induzidos a "publicar bem", o que significa colocar o "resultado de sua produção" numa revista "de qualidade", o que, por sua vez, "qualifica" a produção, o acadêmico, o programa e a instituição. Alguns trechos da entrevista com Juarez Vieira do Nascimento colaboram nessa explicação sobre o interesse pelas "boas publicações" e como isso tem se refletido na produção de artigos nos programas de pós-graduação em educação física:

Eu vejo que a qualidade dos periódicos está impactando na qualidade da formação do pósgraduado, porque os alunos dos programas de pósgraduação também estão publicando, porque um dos critérios de avaliação dos programas - e faz parte de um dos critérios definidores da nota de um programa, é a qualidade das teses e dissertações, que estão vinculadas aos seus resultados, aos seus produtos; e os seus produtos são as suas publicações, ou seja, a sua produção intelectual: artigos, livros, capítulos de livros (NASCIMENTO, 2010).

O mesmo interlocutor se refere sobre o impacto da institucionalização de um "modelo alternativo" de dissertação e tese - a coletânea de artigos -, uma modificação da avaliação da produção dos discentes e seus orientadores, ocorrida, também (ou somente), no âmbito dos periódicos científicos:

Hoje quando tem sido adotado um modelo alternativo de tese e dissertação a partir de um conjunto de artigos a serem publicados. [...] É a estratégia mais frequiente nos programas de pósgraduação da área para atender a essa demanda crescente de produção científica qualificada. A maioria dos programas adota o modelo monográfico, e como opcional o modelo alternativo que é compreende uma coletânea de artigos (NASCIMENTO, 2010).

${ }^{24}$ Consideramos desnecessário sustentar empiricamente.

Movimento, Porto Alegre, v. 16, n. esp, p. 113-154, 2010. 
Se podemos dizer que há um interesse crescente pelas publicações em periódicos (e com sentido), é temerário concluirmos, rapidamente, que o aumento quantitativo do número de submissões leva a uma qualificação das revistas - naquela lógica de que, havendo muitas submissões, é possível selecionar os melhores e incorporálos nos fascículos. É claro, ter um grande número de submissões neste universo das publicações periódicas é sinal de reconhecimento da área. Contudo, em reflexão sobre o índice de rejeição de trabalhos (65\%), o processo de editoração da revista Movimento já levou seus editores a considerarem que "[...] em termos quantitativos, parece que temos tido muito trabalho para pouca produção" (EDITORIAL, 2010c, p. 8). Isto é um indicador de que o interesse em ser avaliado e classificado está na pauta dos pesquisadores-autores, tendo relação com a afirmação de Go Tani de que o aumento do volume de artigos submetidos não significa, necessariamente, de "bons trabalhos" - daí, segundo ele, a necessidade de investir em alguns periódicos para representar a área; Alex Branco Fraga também se refere a isso ao considerar que - em alguns casos - há a busca por publicações somente para que os autores se mantenham nos programas:

A gente não consegue prever para um futuro próximo um aumento substancial no volume de artigos que vão estar circulando pelas revistas para poder melhorar a qualidade por assim dizer. A quantidade até pode, qualidade, não. E nós sabemos que, como pesquisa é qualidade, não tem sentido fazer pesquisa que não tem qualidade, e os critérios de qualidade são critérios internamente estabelecidos, nós que estabelecemos isso, é o parecerista que vai dizer se um artigo pode ser publicado ou não (TANI, 2010).

Tem vários exemplos que tivemos que dizer "não" para os autores [...] que, sabemos, estão em programas de pós-graduação que estão numa linha de excluir as pessoas das ciências sociais. Estão na linha de descredenciar os colegas que são dessas áreas, mas ao mesmo tempo vemos que eles estão, alguns deles, publicando pensando em se manter no programa, o que faz cair a qualidade do artigo (FRAGA, 2010). 
Outro aspecto que nos diz sobre a imbricação visceral entre os periódicos e Programas de Pós-Graduação é a caracterização que Schneider et al. $(2009$, p. 77) fizeram da circulação dos autores na revista Movimento, afirmando que pelos artigos por ela publicados na maior parte oriundos das regiões sul e sudeste - identificava-se uma "endogenia geográfica". Se, de um lado este termo pode ser negativo frente aos critérios dos indexadores, observando-se de forma mais atenta percebe-se que isso está relacionado com os programas de pós-graduação. Os próprios autores que produziram esta interpretação acabam por reconhecer que esta relação é determinante, e o mesmo é referido por Silvana Goellner e Ivone Job: "[...] isso é um movimento da pós-graduação, não é da revista Movimento [...]. É o movimento da produção da nossa Área [...]. Quem está produzindo é sul e sudeste e isso não é específico da revista Movimento, mas qualquer revista da área" (GOELLNER, 2010);

Ele diz que nós temos endogenia autoral por região, que nós temos muitos autores da região sul. Eu discordo um pouco, porque na verdade a endogenia aqui não é endogenia. Endogenia é quando tu produzes alguma coisa para ti mesmo, na publicação científica uma revista endogênica é uma revista que é feita para os seus editores, para a sua comunidade escrever [...]. Então, a região sul tem muitas Instituições da Educação Física e isso se tu fores analisar tem em outras revistas também, mesmo sediadas em São Paulo, no Rio de Janeiro, a endogenia é mais da região sul, sudeste. Então, não vejo [a revista Movimento] como uma revista endogênica [...] (JOB, 2010).

Em síntese, estes aspectos foram apresentados para demonstrar como os periódicos funcionam intimamente vinculados aos programas de pós-graduação em educação física, estando entre eles estabelecida uma imbricação visceral relacionada aos seus docentes e discentes: grande parte dos que "fazem a pós-graduação" também "fazem os periódicos"; grande parte dos que "fazem os periódicos" também "fazem a pós-graduação". 


\section{MOVIMENTO: UM PERIÓdICO QUE "SE FAZ"}

Se, por um lado, este reconhecimento da revista Movimento no âmbito da CAPES e dos programas de pós-graduação da área de educação física, a legitima como um espaço representativo "das pesquisas/linhas socioculturais", por outro, ele também fortalece a própria dinâmica interna de funcionamento do periódico: ele passa a receber maior número de submissões, chamando a atenção dos orientadores e orientandos; ele pode contar com o interesse de "bons" avaliadores; ele pode participar de editais de financiamentos; entre outros aspectos. Por essas razões também há o interesse da revista Movimento (e de outras) em ocupar este posicionamento no campo.

O pressuposto é que a revista Movimento (e seus agentes) adquire sentido legítimo num campo de disputas, investindo capitais adquiridos/incorporados nas ações anteriores, em estratégias ulteriores, sendo assim um periódico que "se faz"25. Esta referência à disputa para que a revista fosse/seja reconhecida no campo da educação física (e este em relação aos outros) está presente no discurso dos editores e ex-editores e permeia os bastidores de produção do periódico. Nesse contexto, a seguinte afirmaçãoreclamação do ex-editor Vicente Molina Neto, goza de pleno sentido:

[...] sempre tivemos que brigar muito pela revista Movimento, pela afirmação dela, seja com os avaliadores da CAPES, seja com o CNPQ, seja com o pessoal das "duras" [ciências biomédicas], nós sempre tivemos que brigar muito para convencer as pessoas de que a nossa revista era uma revista de qualidade, porque "virava e mexia" eles criavam um mecanismo para nos tirar "fora da jogada". Eles, que eu digo são, vamos dizer assim, a hegemonia, o establishment da educação física (MOLINA NETO, 2010).

\footnotetext{
${ }^{25} \mathrm{O}$ "se faz" tem aqui o sentido da estratégia que se dá num espaço da razão prática, que é de disputa, de jogos: uma "[...] invenção permanente, indispensável para a tomada de posição no espaço social" (BOURDIEU, 1990, p. 81).
} 
É nessa direção que consideramos que existem determinados capitais periodísticos ${ }^{26}$ que estão na base deste posicionamento, os quais foram e continuam sendo buscados pelos editores da revista Movimento ${ }^{27}$. Um deles é o seu escopo especializado. O interlocutor Vicente Molina Neto comentou sobre a decisão de especialização da revista, afirmando que ela

[...] ajudou a dar a identidade para a revista [...], consolidou o logo da revista, a marca da revista e começou a ter apelo junto à comunidade científica [...], o pessoal das humanas que não conseguia publicar na Revista Brasileira de Ciências do Esporte não tinha onde publicar e com a especialização da Movimento, eles passaram a ter um outro lugar, então nós começamos a ter demanda desta área [...] (MOLINA NETO, 2010).

Sobre isso, ao falar dos pontos fortes deste periódico, Juarez Vieira do Nascimento afirma que ele atende "[...] não a demanda de si própria ou da própria UFRGS, mas sim de atender a demanda emergente da área". A orientação para os estudos e conhecimento no âmbito das socioculturais, conforme Valter Bracht, "[...] deve ser destacado e deve ser aplaudido [...]", pelo seu impacto no equilíbrio (de poder) entre as subáreas da educação física.

Mas o capital simbólico (reconhecimento) de um periódico também depende consideravelmente da extensão da rede relativamente durável de relações externas que consegue mobilizar e do capital acadêmico vinculado a esta rede. Nesse aspecto, produzir um periódico significa arregimentar colaboradores "adequados" à lógica de funcionamento do campo, o que, na produção da revista

\footnotetext{
${ }^{26}$ Não tendo encontrado expressão melhor, o que chamamos de capitais periodísticos refere-se a propriedades específicas atuantes no campo acadêmico, com especificidades ligadas ao periódicos, nesse caso, dos periódicos em educação física. Esta análise interpretativa está baseada, também, na obra de Pierre Bourdieu, que considera o capital como uma espécie de energia social, determinando as probabilidades de ganhos, contribuindo para a tomada de posição no campo, para a manutenção ou transformação da estrutura do espaço social (BOURDIEU, 1998, 2004b).

${ }^{27}$ Citaremos e analisaremos alguns destes capitais (o foco especializado do escopo; a rede social de avaliadores e autores reconhecidos; os indexadores e os bancos de dados), mas outros também são relevantes e não puderam ser tratados pelos limites que tem um artigo.
} 
Movimento se traduz no esforço constante de selecionar "bons" autores/trabalhos e agregar "bons" avaliadores/pareceres, assim compor seus fascículos com trabalhos capazes de chamar a atenção para assuntos necessários de serem abordados. Esta foi uma posição de Valter Bracht para dizer sobre a importância do periódico e também para fazer uma crítica:

Eu já vi em muitos cursos de graduação aquela discussão sobre o que é educação física, ou mesmo sobre o esporte de rendimento na escola sendo objeto, os textos daquelas polêmicas ${ }^{28}$ sendo debatidos em cursos de graduação. Então me pareceu uma estratégia bem interessante; mas, eu acho que em grande parte devido à essa pressão para assumir as características de periódico dito científico, fez com que essa estratégia tenha sido deixada um pouco de lado (BRACHT, 2010).

Contudo, apesar da ausência da seção Temas Polêmicos, a noção de "trabalhos capazes de chamar a atenção para temas necessários", continua sendo uma referência na seleção dos artigos que serão incorporados na revista. É o que se observa, por exemplo, na preocupação do editor Alex Branco Fraga, ao tratar de conversas que estabeleceu com avaliadores a título de orientação destes quanto à recomendação de rejeição: "[...] o artigo teria condições de ser citado por outras pessoas? Seria um artigo que daria um aporte de discussão para uma dissertação, para outro artigo? Ele seria citado por outros autores? Ele acrescentaria na discussão da área?"

Nessas questões apresentadas pelo editor ao avaliador, notase que além de chamar a atenção para temas há uma preocupação com a noção de trabalho de referência para outros. Tal indicador também foi apontado pela pesquisadora e ex-editora Silvana Goellner, para dizer que a qualidade da Movimento não é redutível aos seus vários indexadores, pois, fora isto, seus textos chamam a atenção:

${ }^{28} \mathrm{Bracht}$ refere-se a temas debatidos na seção "Temas Polêmicos", que foi extinta em 2002 (v. 8, n. 1). 
[...] os textos da Movimento são textos que servem de referência, por exemplo, na questão de gênero que é uma questão que eu trabalho um pouco mais, a revista Movimento é a que mais publicou artigos relacionados com essa temática e são textos que são referências dos meus alunos de mestrado e de doutorado. (GOELLNER, 2010)

Para que haja esse reconhecimento os editores contam com a colaboração dos avaliadores e seus pareceres, no que se refere à aceitação (ou não) de trabalhos. Isso não significa "terceirizar a decisão" (FRAGA, 2010), mas contar com a consulta a um agente especializado (que tem domínio reconhecido na área do trabalho), designado para esta tarefa. A colaboração, nos termos bourdieusianos, retrata uma espécie da capital social mobilizado para selecionar, com autoridade, os trabalhos que farão parte dos fascículos, mas também para fazer reconhecer a legitimidade da decisão editorial, sustentada em pareceres consubstanciados. É por essa razão que não são raras as vezes em que 3, 4 e até mesmo 5 pareceristas são designados para a avaliação de um trabalho, a fim de que se faça a seleção mais "adequada", ou seja, "ratificada" pelos pares e "mediada" pelos editores.

Consoante a essa demanda de avaliações, o corpo de avaliadores consubstanciam, também, o capital simbólico da revista, já que o campo não só classifica os artigos, mas também aqueles que têm autoridade para classificá-los. No caso da Movimento são mais de 300 pessoas cadastradas, fundamentalmente professorespesquisadores com título de doutorado. Muitos destes agentes foram arregimentados após a sua especialização (sobretudo no âmbito da pós-graduação stricto sensu), fazendo com que houvesse uma modificação no corpo editorial, isto é, "[...] compor um grupo de pessoas que poderiam ser os pareceristas e pensar uma política da revista com uma densidade muito forte nas ciências sociais e humanas" (GOELLNER, 2010). E, na medida em que o corpo editorial foi se especializando, "[...] os níveis de exigência [para 
publicação] começaram a aumentar" (MOLINA NETO, 2010), o que também, dentro da lógica de funcionamento do campo acadêmico, colabora no reconhecimento ${ }^{29}$.

Em vista desse reconhecimento e do interesse das revistas da educação física que, dentro da área 21 , buscam melhorar sua posição relativa no campo das publicações periódicas, acaba por existir uma disputa tensa, pois "[...] são várias as revistas, vários os editores que almejam esse lugar de ser uma revista de excelência, de ter uma melhor classificação dentro da CAPES" (GOELLNER, 2010). Em tal disputa, as possibilidades dos periódicos nacionais e específicos da área figurarem nas "melhores" classificações (estratos A1, A2 e B1) são, ainda, bastante reduzidas, pois dependem de indexações internacionais e de "fatores de impacto", aspectos (capitais) que somente nos últimos anos passaram a fazer parte da agenda dos editores das revista nacionais.

Há, também, o que Juarez Nascimento denominou de um "inflacionamento" do Qualis-Periódicos da área, derivado do envolvimento de pesquisadores da fisiologia, bioquímica, por exemplo, nos programas de pós-graduação em educação física e que publicam em revistas internacionais "fora da área", mas que são consideradas na classificação do Qualis. Soma-se a isso, o fato de que existe uma normativa de "travas" do número de revistas em cada um destes "melhores" estratos ${ }^{30}$, que impõe limites de "vagas". O resultado disso é que grande parte dos periódicos melhores classificados são internacionais e de "fora da área". Um trecho da entrevista com Juarez Nascimento ajuda a explicar melhor essa questão:

[Há programas que possuem] quantidade expressiva de docentes que são vinculados historicamente à educação física, com formação inicial e continuada

\footnotetext{
${ }^{29}$ Rejeitar em torno de $70 \%$ dos artigos submetidos e, ainda assim, conseguir publicar 60 trabalhos por ano (em 4 fascículos), além de uma dimensão técnica/seletiva, consubstancia o valor simbólico, o reconhecimento da revista Movimento (vinculado a sua capacidade de socialização, avaliação/classificação e representatividade).

${ }^{30}$ Por determinação do Of. Circular 049/2009/PR/CAPES, "a somatória dos periódicos em estratos $A 1$ e $A 2$ não deve ultrapassar $26 \%$ do total de periódicos estratificados, e a somatória dos periódicos em estratos A1, A2 e B1 não deve ultrapassar $50 \%$ do total de periódicos estratificados" (CAPES, 2010a, p. 3).
} 
nessa área [...]. Agora, tem outros programas que possuem docentes que não estão historicamente envolvidos com a nossa área. Eles vêm principalmente das áreas biológicas, principalmente das áreas básicas. E, como eles publicam em periódicos das áreas básicas, eles vão querer publicar em periódicos em áreas consolidadas, de alto impacto. Esta situação inflaciona os pontos de corte do Qualis da área, limitando os percentuais que nós vamos ter em determinado estrato. Nesse triênio nós tivemos poucos periódicos específicos da área de educação física no estrato A1, assim como no estrato A2. A maioria dos periódicos que são específicos da nossa área e que têm uma contribuição muito importante foram estratificados em B1, porque o índice de impacto deles nas bases indexadoras são ainda considerados baixos [...]. (NASCIMENTO, 2010)

Diante da pouca representatividade dos periódicos nacionais e específicos nos "melhores" estratos da própria área, numa reunião do Fórum de Coordenadores de Programas de Pós-Graduação e Editores de Revistas, realizado no ano de 2009, em Florianópolis, decidiu-se incluir revistas consideradas representativas da melhor produção da área. Nesse esforço de "valorizar" periódicos para impulsionar o "desenvolvimento" da área, a revista Movimento (UFRGS) e a revista Motriz (UNESP), ainda que não tivessem seus "fatores de impacto" divulgados - recentemente tinham sido indexadas no ISI Web of Knowledge - passaram para a classificação B1, juntamente com a Revista Brasileira de Medicina do Esporte. Isto não ocorreu sem refletir disputas e estratégias de convencimento, como explicou Silvana Goellner ao tratar da relação entre os programas de pós-graduação e os periódicos da área:

Então a gente viu claras vezes que a área não reconhecia a revista Movimento e que pela coisa mais literal, critério mais literal do índice de impacto, do indexador, um ou outro, estar relacionado com ela. A revista, se ela também teve essa classificação, foi por força de seus editores e pelo movimento político que os editores fizeram junto à Área $21 \mathrm{e}$ junto à educação física, principalmente quando a 
revista entra no Lilacs - se não me engano foi o primeiro indexador -, e depois no ISI, porque o fato de entrar no ISI, segundo alguns autores e colegas, não garantiria que ela já tivesse um conceito alto, porque ela não tem índice de impacto, porque os critérios que se adotam são esses. Então sempre foi uma relação tensa e sempre foi uma relação também de mostrar que a revista era fundamental para a área e não conceituar a revista com aquilo que ela merece, que ela tem galgado, seria prejudicar toda uma área de conhecimento. Então acho que aquele primeiro movimento que a gente fez, se não me engano em 2005,2006 , que a revista não foi reconhecida quando ela teve um primeiro plus, com uma pontuação melhor dentro da própria área 21 , então teve toda uma movimentação política que acabou impactando na área e que houve esse primeiro momento de melhoria da área, mas ao ponto de chegar numa reunião de fórum de coordenadores e eleger quais eram as revistas que seriam impulsionadas. A Movimento foi considerada como a revista dentro da nossa área que deveria ser potencializada, mas a gente vê uma série de coisas que acontecem: outras revistas entram no SciELO e a Movimento não entra; revistas que nem cumprem os critérios mínimos que aparentemente o SciELO exige. Então é uma disputa de poder que tem na área, exatamente pela repercussão que isso tem em termos de financiamento das próprias revistas, em termos de status acadêmico para os seus editores e para as Instituições nas quais elas estão vinculadas (GOELLNER, 2010).

O que esta situação da revista Movimento reflete não se resume ao atendimento de critérios dos indexadores ou da CAPES, mas fundamentalmente o reconhecimento do que seria o "desenvolvimento" de uma área de conhecimento no âmbito dos programas de pós-graduação em educação física - a dos estudos "socioculturais e pedagógicos".

Atualmente a revista Movimento está indexada em quatro importantes instituições que prestam serviços dessa natureza (Scopus; ISI Web of Knowledge; Latindex; Lilacs), está presente em quatro 
bases de dados (SPORTDiscus; Redalyc; Laptoc; Periódicos CAPES) e figura com o conceito B1 na classificação do QualisPeriódicos CAPES, na área da educação física. Contudo, se, por um lado a presença da revista em indexadores e bancos de dados são "desejados" e também motivos de comemoração, por outro, são vistos com desconfiança por um dos entrevistados. Valter Bracht posicionou-se de maneira crítica frente a estes elementos, argumentando sobre o distanciamento dos próprios problemas da intervenção em educação física, quando os periódicos passam a operar apenas segundo as lógicas do campo científico ou dos programas de pós-graduação. Citando exemplos de mudanças ocorridas em revistas da área de educação física, para atender as demandas dos indexadores, Bracht usa a expressão "caindo numa vala comum" ao tratar da referência que se tem dos indexadores. Nesse sentido, este pesquisador reclama de uma produção dos periódicos relativamente centrada neles mesmos e não em importantes necessidades desse campo de intervenção pedagógica. A posição desse interlocutor alerta para o fato de que esses capitais não são específicos do campo da educação física, mas acabam sendo extremamente atuantes neste, ainda que, relativamente, reconvertidos ou mediatizados pelas lógicas deste campo.

Nesta crítica, Bracht também menciona a revista Movimento, quando trata da ausência da seção Temas Polêmicos, deixada de lado, segundo este pesquisador, em face à pressão para "assumir características ditas científicas". Isto foi, de certa forma, confirmado pelo ex-editor da revista, Vicente Molina Neto, ao afirmar que "[...] quando a CAPES começou a se interessar pelos periódicos, tinham algumas orientações que diziam: 'Temas Polêmicos não é bom para a revista porque são artigos de opinião, então não vale à pena". Corrobora isso, o fato de que os indexadores são taxativos quanto a imperiosidade da predominância de artigos originais, resultantes de pesquisa.

O que esta crítica apresentada por Valter Bracht nos ajuda a compreender é que há um modo dominante de operar este jogo de conversões e que também há uma série de capitais válidos, que, 
mesmo tendo forte influência no campo, nem sempre são reconhecidos como arbitrários. A estrutura do campo acadêmico funciona segundo estas regras e a revista Movimento não está fora deste jogo.

\section{Considerações FinaIS}

Esse trabalho teve o objetivo de compreender como ocorreu o processo da produção/repercussão da revista Movimento a partir do momento em que se especializou como um periódico da educação física em interface com as ciências humanas e sociais. A partir disso, buscamos respostas para questões que versaram sobre o sentido dos periódicos científicos na relação com o campo acadêmico/ científico da educação física e com os seus programas de pósgraduação e sobre o sentido da revista Movimento nesse contexto. Essas respostas foram alcançadas com base em dados obtidos através de entrevistas semi-estruturadas e análise de documentos, esses articulados com o olhar da sociologia da ciência e da teoria do campo científico, na perspectiva de Pierre Bourdieu.

Inicialmente, foi possível perceber que a revista Movimento vem se constituindo num contex to de tensões que existem no campo, esse que é pautado pelas diferenças entre a educação física vista pelas ciências naturais e aquela observada a partir das ciências sociais. A sua posição como uma revista especializada tem o seu lugar, porque emergiu num momento em que o campo da educação física consolida o debate sociocultural sobre seus fazeres e saberes; ao mesmo tempo, a Movimento criou o seu lugar, porque ajudou a consolidar a participação (ou o posicionamento) de uma subárea de conhecimento neste campo - de certa forma tem colaborado para equilibrar as disputas e as cisões do campo.

Ela assume, então, além do sentido de socialização do conhecimento, um sentido de representatividade e de avaliação/ classificação no campo, com profundos vínculos com a pósgraduação, com quem tem uma imbricação visceral: se, por um lado, são os pesquisadores das sociais que atuam na pós-graduação que 
fazem a revista Movimento, por outro, é a revista Movimento que ao oferecer espaço para publicações das sociais - contribui para que esses pesquisadores (e suas linhas) se mantenham na pósgraduação.

Isso não ocorreu de maneira despropositada, mas faz parte de um processo que - mesmo que não tenha sido feito de forma planejada - se impulsiona no momento de sua especialização e compreende outros esforços, como: a estruturação de uma equipe especializada; a captação de recursos externos; a publicação online em inglês e espanhol; a procura de um corpo de avaliadores especializados; e a busca por indexações (atendendo aos seus critérios).

Ainda que alguns destes esforços possam sugerir que a Movimento se submete a uma lógica dominante, reconhecendo e operando segundo forças objetivas atuantes no campo acadêmico, destaca-se que isso é, simultaneamente, produto e resultado do seu desenvolvimento e do desenvolvimento da subárea das socioculturais. Com base em depoimentos dos nossos interlocutores, procuramos mostrar que a participação efetiva no jogo foi um aspecto fundamental para a sua consolidação. Isso porque, mesmo que muitas vezes ouçamos que "a CAPES (e a Educação Física) somos nós", esse "nós" não tem se mostrado homogêneo e está profundamente constituído por conflitos e por relações de poder, que acabam por refletir na legitimação do que é uma "boa revista".

Assim, a revista Movimento, dentro do espaço acadêmico da educação física, não foi apenas uma intermediária, por onde "passam artigos". Mais do que isso, sobretudo pela sua decisão de especialização do escopo e da política editorial adotada, ela tornouse mediadora de um processo que, simultaneamente, a constituiu. E foi nesse sentido que ela se consolidou como um importante capital acadêmico no campo da Educação Física Brasileira. 
Revista Movimento: analysis of the meanings
and repercussions of a journal that "builds
itself" in the field of Brazilian Physical Education Abstract: Identifying the journal Movimento as an institution linked to the history of the School of Physical Education of the Federal University of Rio Grande do Sul, this article intends to understand how the process occurred in its production/impact, from the moment in which it specialized as a physical education journal in interface with the human and social sciences (20032010). The responses linked to this objective were obtained from analysis of semi-structured interviews with editors and former editors of the journal, as well as people highlighted in the academic/scientific context of Brazilian Physical Education; documents related to periodic production in general, to the journal Movimento in particular, were also analyzed. It can be concluded that the specialization process of the journal is linked to the tension in the academic/scientific field of Brazilian Physical Education. The meaning of this journal is not reducible to the socialization of knowledge, but it also includes a meaning of representativeness and evaluation/classification in the field, with deep ties to the graduate program, with which it has a visceral overlap. This was part of a process that propels itself at the time of its specialization and other efforts related to the logic of the scientific field. The journal Movimento is thus a result and product of its development and of the development of the sociocultural subfield, where it is established as a capital.

Keywords: Journals as the subject. History. Physical Education. Sociology. 
Revista Movimento: análisis de los sentidos y de la repercusión de un periódico que "se realiza" en el campo de la Educación Física brasileira

Resumen: Identificando la revista Movimento como una institución vinculada a la historia de la Escuela de Educación Física de la Universidad Federal de Rio Grande do Sul, en este artículo tratamos de comprender cómo ocurrió el proceso de su producción/ repercusión, a partir del momento en que se especializó como un periódico de la educación física en interfaz con las ciencias humanas y sociales (20032010). Las respuestas vinculadas a ese objetivo se obtuvieron a partir de análisis de entrevistas semiestructuradas realizadas con editores y exeditores del periódico, así como con personas en destaque en el contexto académico/científico de la Educación Física Brasileña; se analizaron también documentos vinculados a la producción periódica en general a la revista Movimento en particular. Es posible concluir que el proceso de especialización de la revista se vinculó a la tensión existente en el campo académico/científico de la Educación Física Brasileña. El sentido de este periódico no se reduce a la socialización del conocimiento, sino engloba también, un sentido de representatividad y de evaluación/ clasificación en el campo, con profundos vínculos con el postgrado, con quien tiene una imbricación visceral. Esto forma parte de un proceso que se impulsa en el momento de su especialización y otros esfuerzos vinculados a las lógicas del campo científico. La revista Movimento es, por lo tanto, producto y resultado de su desarrollo y del desarrollo de la subárea sociocultural, donde se consolida como un capital.

Palabras clave: Publicaciones periódicas como asunto. Historial. Educación Física. Sociología. 


\section{REFERÊNCIAS}

BOURDIEU, P. O campo científico. In: ORTIZ, R. Pierre Bourdieu: sociologia. São Paulo: Ática, 1983a.

Algumas propriedades dos campos. In: BOURDIEU, P. Questões de sociologia. Rio de Janeiro: Marco Zero, 1983b.

Economia das trocas simbólicas. 2. ed. São Paulo: Perspectiva, 1987.

Coisas ditas. São Paulo: Brasiliense, 1990.

O poder simbólico. 2. ed. Rio de Janeiro: Bertrand Brasil, 1998.

Os usos sociais da ciência: por uma sociologia crítica do campo científico. São Paulo: UNESP, 2004a.

2004b.

Razões práticas: sobre a teoria da ação. 5. ed. Campinas: Papirus,

Para uma sociologia da ciência. Lisboa: Edições 70, 2008a.

Economia das trocas lingüísticas: o que falar quer dizer. 2. ed. 1. reimp. São Paulo: Edusp, 2008b.

O senso prático. Rio de Janeiro: Vozes, 2009.

CAPES. COORDENAÇÃO DEAPERFEIÇOAMENTO DE PESSOALDENÍVELSUPERIOR. Documento de área 2009. Disponível em: <http://www.capes.gov.br/sobre-acapes/historia-e-missao>. Acesso em: 20 dez. 2010a.

Roteiro para classificação de livros: avaliação dos Programas de Pós-Graduação. Disponível em: http://www.capes.gov.br/images/stories/download/ avaliacao/Roteiro_livros_Trienio2007_2009.pdf. Acesso em: 20 dez. 2010b.

História e missão. Disponível em: <http://www.capes.gov.br/sobre-acapes/historia-e-missao>. Acessado em: 20 de dezembro de 2010c.

CNPQ. CONSELHO NACIONAL DE DESENVOLVIMENTO CIENTÍFICO E TECNOLÓGICO. O CNPq: apresentação. Disponível em: < http://www.cnpq.br/ cnpq/index.htm>. Acesso em: 20 dez. 2010.

DAOLIO, J. O ser e o tempo da pesquisa sociocultural em educação física. Revista Brasileira de Ciências do Esporte, Campinas, v. 29, n. 1, p. 49-60, set., 2007.

EDITORIAL. Movimento, Porto Alegre, v. 15, n. 3, p. 7-10, 2009a.

EDITORIAL. Movimento, Porto Alegre, v. 15, n. 2, p. 7-10, $2009 \mathrm{~b}$.

EDITORIAL. Movimento, Porto Alegre, v. 16, n. 3, p. 7-8, 2010c. 
GEERTZ, C. Nova luz sobre a antropologia. Rio de Janeiro: Jorge Zahar, 2001.

KERR-PONTES, L. R. S. et al. Uma Reflexão sobre o Processo de Avaliação das Pós-graduações Brasileiras com Ênfase na Área de Saúde Coletiva. Physis: Revista de Saúde Coletiva, Rio de Janeiro, v. 15, n.1, p.83- 94, jan./jun., 2005.

KOKOBUN, E. Pós-Graduação em Educação Física no Brasil: indicadores objetivos dos desafios e das perspectivas. Revista Brasileira de Ciências do Esporte, Campinas, v. 24, n. 2, p. 9-26, jan., 2003.

KUENZER, A. Z.; MORAES, M. C. M. de. Temas e tramas na Pós-Graduação em Educação. Educação \& Sociedade, Campinas, v. 26, n. 93, p. 1341-1362, set./ dez., 2005.

LOVISOLO, H. R. "Levantando o sarrafo ou dando tiro no pé": critérios de avaliação e qualis das pós-graduações em Educação Física. Revista Brasileira de Ciências do Esporte, Campinas, v. 29, n. 1, p. 23-33, set., 2007.

MANOEL, de J. E.; CARVALHO, M. Y. Pós-Graduação na Educação Física Brasileira: A atração (fatal) para a biodinâmica. Educação e Pesquisa, São Paulo, v. 37, n. 2, mai./ago., 2011.

MOREIRA, C. O. F.; HORTALE, V. A.; HARTZ, Z. de A. Avaliação da pós-graduação: buscando consenso. Revista Brasileira de Pós-Graduação, Brasília, DF, n. 1, p. 26-40, jul., 2004.

MOVIMENTO. Revista da Escola de Educação Física da UFRGS. Capa. Disponível em: <http://seer.ufrgs.br/Movimento/index>. Acessado em: 20 de dezembro de 2010.

PERIÓDICOS CAPES. Acervo. Coleções. Disponível em <http:// www.periodicos.capes.gov.br/?option=com_pcollection \&mn=70\&smn=79>Acesso em: 27 dez. 2010.

POPPER, K. R. Conhecimento objetivo: uma abordagem revolucionária. Belo Horizonte: Itatiaia; São Paulo: EdUSP, 1975.

SCHNEIDER, Omar et al. Arqueologia das práticas editoriais: 15 anos de um impresso em Movimento. Movimento, Porto Alegre, v. 15, n. 3, p. 57-85, 2009.

SCIELO. Scientific Electronic Library Online. SciELO. Disponível em: <http:// www.scielo.br/scielo.php?script=sci_home\&lng=pt\&nrm=iso> Acesso em: $27 \mathrm{dez}$. 2010.

TANI, G. Educação Física: por uma política de publicação visando à qualidade dos periódicos. Revista Brasileira de Ciências do Esporte, Campinas, v. 29, n. 1, p. 9-22, set., 2007.

THOMSON REUTERS. Products \& Services. Products A-Z. Disponível em <http:/ /thomsonreuters.com/products_services/science/science_products/a-z/> Acesso em: 27 dez. 2010. 


\section{ENTREVISTAS}

BRACHT, Valter. Revista Movimento: depoimento [18 de outubro, 2010]. Porto Alegre: Escola de Educação Física - UFRGS. Entrevista concedida a Mauro Myskiw.

FRAGA, Alex Branco. Revista Movimento: depoimento [17 de setembro, 2010]. Porto Alegre: Escola de Educação Física - UFRGS. Entrevista concedida a Mauro Myskiw e Maitê Venuto de Freitas.

GOELLNER, Silvana. Revista Movimento: depoimento [21 de setembro, 2010]. Porto Alegre: Escola de Educação Física - UFRGS. Entrevista concedida a Mauro Myskiw e Maitê Venuto de Freitas.

JOB, Ivone. Revista Movimento: depoimento [08 de setembro, 2010]. Porto Alegre: Escola de Educação Física - UFRGS. Entrevista concedida a Mauro Myskiw.

MOLINA NETO, Vicente. Revista Movimento: depoimento [03 de setembro, 2010]. Porto Alegre: Escola de Educação Física - UFRGS. Entrevista concedida a Mauro Myskiw e Maitê Venuto de Freitas.

NASCIMENTO, Juarez Vieira do. Revista Movimento: depoimento [29 de setembro, 2010]. Porto Alegre: Escola de Educação Física - UFRGS. Entrevista concedida a Marco Paulo Stigger e Mauro Myskiw.

TANI, Go. Revista Movimento: depoimento [30 de setembro, 2010]. Porto Alegre: Escola de Educação Física - UFRGS. Entrevista concedida a Marco Paulo Stigger e Mauro Myskiw. 
